\title{
Exposición a Solventes Orgánicos y Efectos Genotóxicos en Trabajadores de Fábricas de Pinturas en Bogotá
}

\author{
Bogotá paint-industry workers' exposure to organic solvents and \\ genotoxic effects \\ Omayda Cárdenas-Bustamante ${ }^{1}$, Marcela Varona-Uribe ${ }^{1}$, Rosa I. Patiño-Florez², \\ Helena Groot-Restrepo ${ }^{3}$, Diana Sicard-Suárez ${ }^{3}$, María M. Tórres-Carvajal ${ }^{3}$ y \\ Darío Pardo-Pardo ${ }^{1}$
}

1. Laboratorio Salud Ambiental, Instituto Nacional de Salud, Bogotá, D.C. ocardenas@ins.gov.co

2. División de Investigaciones, Universidad El Bosque, Bogotá, D.C. isabelpatino@gmail.com 3. Laboratorio de Genética Humana, Universidad de los Andes Bogotá, D.C. hgroot@uniandes.edu.co

Recibido 8 Agosto 2006/Enviado para Modificación 4 Abril 2007/Aceptado 10 Mayo 2007

\section{RESUMEN}

Objetivo Investigar la exposición a solventes orgánicos y los efectos genotóxicos mediante monitoreo citogenético determinando la frecuencia de micronúcleos en linfocitos y el daño del ADN por el ensayo del cometa, en trabajadores de fábricas de pinturas en Bogotá.

Metodología Como biomarcadores de exposición a benceno, tolueno y xileno, la excreción de fenol, ácido hipúrico y ácido metilhipúrico fue investigada en muestras de orina provenientes de trabajadores en dos fábricas de pinturas en Bogotá y de un grupo control. También se realizó monitoreo de la concentración de benceno, tolueno y xileno en el ambiente de trabajo. Como biomarcadores de efectos genéticos tempranos, la frecuencia de micronúcleos y rompimiento de cadenas simples de ADN fueron evaluadas en células mononucleares a partir de muestras de sangre periférica.

Resultados Las concentraciones de ácido hipúrico en orina post-exposición se encontraron dentro de los rangos normales, mientras que para fenol el 3,3 \% y para ácido metilhipúrico el $50,8 \%$ de las muestras presentaron niveles por encima de los valores de referencia. En una de las fábricas la concentración de benceno en aire estaba por encima de los valores límites permisibles. No hubo diferencias estadísticas entre los trabajadores expuestos y los no expuestos con relación a los biomarcadores genéticos examinados.

Conclusiones En este estudio los niveles de solventes orgánicos internamente efectivos parecen ser bajos lo cual se explica con la ausencia de efectos genotóxicos en las células examinadas. Este trabajo constituye un aporte para continuar investigando sobre el tema y a la vez hacer seguimiento por medio del programa de vigilancia epidemiológica. 
Palabras Clave: Pinturas, exposición, Pruebas de Micronúcleos, Ensayo Cometa (fuente: DeCS, BIREME).

\section{ABSTRACT}

Objective Investigating the degree of exposure to organic solvents and related genotoxic consequences in paint-factory workers by using cytogenetic monitoring and determining micronuclei frequency in lymphocytes and DNA damage as assessed by comet assays.

Methodology Excretion of phenol and hippuric and methylhippuric acids in urine was investigated as biomarkers for benzene, toluene and xylene exposure. Urine samples were taken in two paint-factories in Bogotá and in a non-exposed control group. Benzene, toluene and xylene concentrations in air were measured in the work setting. Micronuclei and simple DNA chain breakage frequency were evaluated in peripheral blood sample mononuclear cells to assess early genetic effects.

Results Hippuric acid concentration was found to be within normal values; by contrast, phenol and methylhippuric acid sample concentrations were above normal values by $3,3 \%$ and $50,8 \%$, respectively. Benzene concentration in air was above permissible limits in one of the factories. There were no statistical differences regarding genetic biomarkers between exposed and non-exposed workers.

Conclusions Organic solvent levels in the samples were apparently low, which is consistent with the absence of genotoxicity in cells. This study represents a step forward in research in occupational health surveillance.

Key Words: Paint, exposure, micronucleus tests, comet assay (source: $M e S H$, NLM).

$\mathrm{L}$ os solventes orgánicos interactúan con los ácidos nucleicos produciendo efectos genéticos de manera inmediata y a largo plazo (mutagénesis y/ o carcinogénesis). Se ha mostrado el efecto clastogénico e incremento de aberraciones cromosómicas estructurales en trabajadores expuestos a benceno y tolueno (1-4). El biomonitoreo de poblaciones ocupacionalmente expuestas a sustancias genotóxicas como los solventes orgánicos, tiene el propósito de detectar efectos genéticos tempranos que alertan sobre el riesgo de exposición. Entre los biomarcadores más empleados está la prueba de micronúcleos (MN), la cual permite detectar aneuploidía o clastogenicidad (5,615) y el ensayo del cometa o electroforesis en gel de células individuales (SCGE) en condiciones alcalinas, método sensible para medir rompimiento de cadenas sencillas de ADN y sitios lábiles al álcali (4,16-18).

El Instituto Nacional de Salud, realizó estudios encontrando trabajadores con niveles elevados de metabolitos de solventes orgánicos en orina $(19,20)$, por lo cual se desarrollo el presente estudio cuyo objetivo fue investigar la 
exposición a solventes orgánicos y los efectos genotóxicos, mediante la determinación de fenol, ácidos hipúrico y metilhipúrico en orina, así como las concentraciones de BTX en aire del lugar de trabajo y monitoreo citogenético determinando la frecuencia de MN en linfocitos y el daño del ADN por el ensayo del cometa en trabajadores de fábricas de pinturas en Bogotá.

\section{MATERIAL Y METODOS}

\section{Muestra de Estudio}

El presente estudio descriptivo se hizo en 2003, con una muestra de 61 trabajadores (33 con exposición a solventes orgánicos en dos fábricas de pinturas en Bogotá y 28 sin exposición). La muestra fue calculada con la fórmula de muestreo aleatorio simple y se tuvo en cuenta la prevalencia de $\mathrm{MN}(0,8 \%)$, reportada en la literatura para individuos sanos no expuestos a agentes genotóxicos $(13,21)$. Se obtuvo un tamaño de muestra con un poder del $80 \%$, un nivel de significancia del $95 \%$ y un $5 \%$ de pérdidas. Los criterios de inclusión del grupo expuesto fueron: haber trabajado en la empresa mínimo 6 meses, no tener exposición a radiaciones, no haber recibido radioterapia o tratamiento con medicamentos quimioterapéuticos, no presentar enfermedades infecciosas en los últimos seis meses y estar laborando con solventes orgánicos. Para los individuos sin exposición los criterios fueron los mismos, excepto tener contacto con solventes orgánicos. Una vez los trabajadores aceptaron participar voluntariamente y firmaron un consentimiento escrito se realizó una entrevista para la recolección de información demográfica, antecedentes ocupacionales, clínicos, toxicológicos y hábitos alimenticios y se procedió a la toma de las muestras de sangre y orina.

\section{Pruebas citogenéticas}

Se realizaron las pruebas de MN y rupturas en el ADN por el ensayo del cometa. Las muestras se recolectaron antes de iniciar la jornada laboral. Se tomaron $10 \mathrm{~mL}$ de sangre por punción venosa en tubos vacutainer ${ }^{\circledR}$ con heparina sódica como anticoagulante. Las muestras permanecieron refrigeradas hasta su análisis. Parte de la muestra fue empleada para hacer cultivos de sangre total para la determinación de MN para lo cual el bloqueo citocinético se realizó siguiendo el método de Fenech y Morley (21). La frecuencia de MN se reportó en 1000 células binucleadas por trabajador. El ensayo del cometa, se realizó en sangre total y en linfocitos separados con Ficoll-Hypaque (Sigma). La viabilidad de las células después de la separación fue determinada por exclusión del colorante azul de trypan y una viabilidad mayor o igual a 75 \% fue considerada aceptable para realizar el ensayo del cometa, siguiendo la 
metodología desarrollada por Singh NP (22). Se analizaron 100 células por individuo y el daño del ADN fue determinado por la medición de la longitud de la cola (en micras) desde el centro del núcleo hasta el último punto fluorescente visible en la cola.

Determinación de metabolitos de solventes orgánicos en orina Se recolectaron 2 muestras de orina de $50 \mathrm{~mL}$; una pre-exposición (48 horas sin exposición a solventes) y una post-exposición (36 horas después de la exposición inicial), siguiendo la metodología del "National Institute for Occupational Safety and Health" (NIOSH) (23-25). La cuantificación de fenol, ácido hipúrico y metilhipúrico se realizó por extracción ácida, se emplearon muestras de referencia de los laboratorios BIO-RAD ${ }^{\circledR}$ como control interno y se realizó corrección de los resultados por densidad urinaria. El fenol se analizó por cromatografía de gases con detector de ionización por llama de hidrógeno GC-FID (23) y los ácidos hipúrico y metil-hipúrico por cromatografía líquida HPLC con detector UV-VIS (24). Los valores de referencia en orina de personas no expuestas a solventes orgánicos, fueron para fenol hasta $15 \mathrm{mg} / \mathrm{L}$ (26), para ácido hipúrico hasta $1400 \mathrm{mg} / \mathrm{L}$ y ausencia de ácido metilhipúrico $(27,28)$, valores adoptados por el antiguo Ministerio de Salud de Colombia para la población colombiana.

Determinación de solventes orgánicos en aire

El monitoreo ambiental de BTX en aire, se realizó con bombas de muestreo personal (Escort ELF, MSA, Ref. BFE-1272-96), por adsorción de los vapores en tubos de carbón activado de $100 \mathrm{mg} / 50 \mathrm{mg}$ (29). El número de muestras de aire se estimó previo análisis de la población directa e indirectamente expuesta teniendo en cuenta el concepto de grupos homogéneos sugerido por Rock JC (30), que indica que al menos corresponda a la raíz cuadrada de la población del grupo homogéneamente expuesto (GHE). En todos los casos se buscó que el muestreo garantizara la representatividad de la exposición durante una jornada laboral completa, para comparar los resultados encontrados con los niveles de concentración establecidos como umbrales permisibles ponderados en el tiempo (Threshold Limit Values-TLV, Time Weight Average-TWA). La determinación de BTX en aire se realizó siguiendo los métodos del $\operatorname{NIOSH}(29,31)$, empleando para la curva de calibración, estándares referenciados por la EPA(624 GMSConsent Degree Purgeables. Chromatography Reference Guide). Durante el proceso analítico de las muestras se participó en el Programa Interlaboratorios de Control de Calidad de Vapores Orgánicos del Instituto Nacional de Seguridad e Higiene en el Trabajo - Centro Nacional de Verificación de Maquinaria en Baracaldo (Vizcaya, España). Los valores límites permisibles para los solventes 
en aire fueron para benceno ( $0,5 \mathrm{ppm})$, tolueno (50 ppm) y xileno (100 ppm) $(32,33)$.

\section{Análisis estadístico}

Se utilizaron los programas Estata 6.0 y Epi Info 6.04. Se realizó análisis descriptivo mediante frecuencias simples, uso de medidas de tendencia central y dispersión. Igualmente, se hizo análisis de varianza (ANOVA) y la prueba de Ji cuadrado, entre la condición de exposición y todas las variables del estudio incluyendo los resultados en orina y de ensayos citogenéticos, para lo cual se utilizó la prueba estadística F con sus correspondientes valores de p, con el fin de identificar diferencias significativas. Para las mediciones de solventes en aire se realizaron los cálculos de las concentraciones tolerables medias (TLVTWA) ajustadas para las condiciones de trabajo en Colombia aplicando la corrección de Brief Scala indicada en Patty's Industrial Higiene and Toxicology (34).

\section{RESULTADOS}

\section{Muestra de Estudio}

De los 61 trabajadores, el 54,1 \% tenía exposición a solventes orgánicos. Participaron 34 (55,7 \%) hombres y 27 (44,3\%) mujeres, con un promedio de edad de 32,8 años (rango 18 a 65 años, $D E=10,0$ ) y 34,0 años (rango 19 a 55 años, $\mathrm{DE}=9,6$ ) respectivamente. El tiempo medio de trabajo en la empresa fue de 60 meses (rango 1 a 360 meses, DE=91,1). Dieciséis (26,2 \%) trabajadores eran productor-mezclador de pinturas, 9 (14,8 \%) vendedores de pinturas y 8 (13,1\%) personal administrativo, quienes indirectamente presentaban exposición a solventes orgánicos. En el grupo sin exposición los oficios fueron, administradores 10 (16,3\%), secretarias 8 (13,1\%), servicios generales 7 (11,5 \%) y auxiliares de oficina 3 (4,9\%). El 6,6 \% de los trabajadores reportaron el uso del benceno en sus actividades, 11,5 \% tolueno, 9,8 \% xileno, 31,2 \% tiner, $37,7 \%$ varsol y 24,6 \% bóxer. Algunos desarrollaban actividades extralaborales como pintura (14,8 \%), carpintería (6,6 \%) y mecánica (3,3 \%), en las cuales podrían verse expuestos a solventes orgánicos. Veintinueve $(47,5$ $\%)$ trabajadores se cambiaba de ropa de trabajo una vez por semana, sólo 17 $(28,0 \%)$ se cambiaban de ropa de trabajo en caso de salpicaduras con sustancias químicas, 14 (23,0 \%) lavaban la ropa de trabajo en la empresa, el resto 47 (73,0 \%) lo hacían en la casa y de estos el 50,0 \% la lavaban mezclada con el resto de ropa de su familia. De los 16 trabajadores que usaban respirador, sólo cuatro $(25,0 \%)$ lo usaban siempre que manipulaban sustancias químicas y 11 (68,8 \%) refirieron nunca haber cambiado el filtro. En la Tabla 1, se resumen 
otras características de los trabajadores participantes en el estudio.

El 31,2 \% reportaron fumar o haber fumado alguna vez, un promedio de 3,5 cigarrillos al día (rango 1 a 12 cigarrillos por día), sólo el 10,5 \% lo hacían en el lugar de trabajo, un promedio de 2,5 cigarrillos al día, el consumo de licor y enlatados se observó en el 73,8 \% y el 55,7 \% respectivamente. Los signos y síntomas más reportados fueron, resequedad o descamación de la piel $(54,1$ $\%)$, dolor de cabeza (45,9\%), irritación de la piel y dolor de espalda (26,2 \%) e irritación de los ojos (24,6 \%).

Tabla 1. Medidas de higiene y seguridad industrial y uso de elementos de protección personal en los trabajadores participantes, 2003

\begin{tabular}{|c|c|c|c|}
\hline Variable & Características & No. & $\%$ \\
\hline Tipo de ropa & $\begin{array}{l}\text { Uniforme } \\
\text { Bata } \\
\text { Ropa de calle }\end{array}$ & $\begin{array}{l}25 \\
14 \\
22\end{array}$ & $\begin{array}{l}41,0 \\
36,1 \\
22,9\end{array}$ \\
\hline Uso de guantes & $\begin{array}{l}\text { Sí } \\
\text { No }\end{array}$ & $\begin{array}{l}22 \\
39\end{array}$ & $\begin{array}{l}36,1 \\
63,9\end{array}$ \\
\hline Tipo de guantes & $\begin{array}{l}\text { Caucho } \\
\text { Látex (Cirugía) } \\
\text { Cuero, carnaza }\end{array}$ & $\begin{array}{l}9 \\
6 \\
6\end{array}$ & $\begin{array}{l}40,9 \\
27,3 \\
27,3\end{array}$ \\
\hline Uso de respirador & $\begin{array}{l}\text { Sí } \\
\text { No }\end{array}$ & $\begin{array}{l}16 \\
45\end{array}$ & $\begin{array}{l}26,2 \\
73,8\end{array}$ \\
\hline Tipo de respirador & $\begin{array}{l}\text { Vapores } \\
\text { Polvos } \\
\text { "Desechable" }\end{array}$ & $\begin{array}{l}9 \\
2 \\
5\end{array}$ & $\begin{array}{l}56,3 \\
12,5 \\
31,2\end{array}$ \\
\hline Tipo de calzado & $\begin{array}{l}\text { Botas de cuero } \\
\text { Zapatos de cuero }\end{array}$ & $\begin{array}{l}26 \\
35\end{array}$ & $\begin{array}{l}42,6 \\
57,4\end{array}$ \\
\hline $\begin{array}{l}\text { Ingiere alimentos en el } \\
\text { sitio de trabajo }\end{array}$ & $\begin{array}{l}\text { Sí } \\
\text { No }\end{array}$ & $\begin{array}{l}27 \\
34\end{array}$ & $\begin{array}{l}44,3 \\
55,7\end{array}$ \\
\hline $\begin{array}{l}\text { Se lava las manos antes } \\
\text { de comer }\end{array}$ & $\begin{array}{l}\text { Siempre } \\
\text { Ocasionalmente } \\
\text { Nunca }\end{array}$ & $\begin{array}{r}42 \\
13 \\
6\end{array}$ & $\begin{array}{r}68,8 \\
21,4 \\
9,8\end{array}$ \\
\hline $\begin{array}{l}\text { Se ducha al terminar } \\
\text { la jornada }\end{array}$ & $\begin{array}{l}\text { Siempre } \\
\text { Ocasionalmente } \\
\text { Nunca }\end{array}$ & $\begin{array}{r}13 \\
6 \\
42\end{array}$ & $\begin{array}{r}21,3 \\
9,8 \\
68,9\end{array}$ \\
\hline
\end{tabular}

Evaluación de efectos genotóxicos

El 49,2 \% de los trabajadores presentaron MN. En el grupo con exposición, la frecuencia de MN fue hasta 7/1000 células binucleadas y en los trabajadores sin exposición hasta 4/1000 células binucleadas. Con el ensayo del cometa se encontró que el $60 \%$ de los trabajadores presentaron más del $80 \%$ de sus células sin rupturas de cadena sencilla en el ADN, el resto presentaron daños 
bajos en sus células. En sangre total la media de longitud de la cola de migración de ADN en los trabajadores expuestos fue de 30,2 $\mu \mathrm{m}$ (21 a $57 \mu \mathrm{m}$ ) y en los no expuestos de 27,9 $\mu \mathrm{m}$ (23 a $38 \mu \mathrm{m})$. En linfocitos la media de longitud de la cola fue de 35,0 $\mu \mathrm{m}$ (19 a $55 \mu \mathrm{m}$ ) en expuestos y de 33,4 $\mu \mathrm{m}$ (24 a $54 \mu \mathrm{m})$ en no expuestos.

Determinación de metabolitos de solventes orgánicos en orina post-exposición En la muestra de estudio se hallaron niveles de fenol entre no detectable y 20,7 $\mathrm{mg} / \mathrm{L}$ (media=4,96 mg/L, mediana=5,4 mg/L y $\mathrm{DE}=4,9$ ). Niveles de ácido hipúrico desde no detectable hasta 1225,2 mg/L (media=457,4 mg/L, mediana 426,6 mg/L y DE=299,3) y niveles de ácido metilhipúrico entre no detectable y 1209,8 mg/L (media=99,4 mg/L, mediana 17,2 mg/L y DE=217,7). Se encontraron niveles de ácido metilhipúrico, por encima de los valores de referencia en 31 (50,8 \%) trabajadores, con un rango de 17,2 mg/L a 1209,8 $\mathrm{mg} / \mathrm{L}$ (media=195,6 mg/L, mediana=76,8 mg/L y DE=274,6) y para fenol en 2 (3,3 \%) trabajadores, rango 18,4 a 20,7 mg/L (media=19,55 mg/L y DE= 1,626). Ningún trabajador presentó valores anormales de ácido hipúrico en muestras post-exposición.

Características de los trabajadores con niveles altos de metabolitos en orina Treinta y tres trabajadores presentaron metabolitos en orina post-exposición por encima del valor de referencia, 27 tenían exposición y seis no. El promedio de edad fue de 30,4 años (rango entre 18 a 57 años, $\mathrm{DE}=8,5$ ), el tiempo promedio de trabajo en la empresa fue de 61,2 meses. Los oficios reportados por estos trabajadores fueron productor-mezclador de pinturas en un 38,7 \%, vendedor de pinturas 25,8 \% y administrativos $19.4 \%$, personal que se encuentra indirectamente expuesto ya que sus oficinas se encontraban dentro del área de producción de las pinturas. El 9,0 \% reportaron el uso de benceno y 19,4 \% tolueno y xileno, el 51,6 \% de los trabajadores reportaron el uso de tiner y $60 \%$ varsol, pinturas, pegantes y disolventes de pinturas en actividades extralaborales. Sólo el 16,1 \% reportó uso de elementos de protección personal para el manejo de solventes orgánicos. El 41,9 \% consumían alimentos en el sitio de trabajo, 22,6 \% fumaba, 77,4\% consumía licor y 48,4\% enlatados de manera frecuente. Los síntomas reportados por estos trabajadores fueron resequedad o descamación de la piel 45,2 \% y dolor de cabeza 38,7 \%.

Determinación de solventes orgánicos en aire

Las concentraciones de BTX en aire se encontraron dentro de los valores límites permisibles según los valores de la Conferencia Americana Gubernamental de Higienistas Industriales (ACGIH), aceptados para Colombia. 
Sólo un punto de muestreo en el área de producción de una empresa mostró concentraciones de benceno en aire por encima de los límites aceptados (Tabla 2).

Tabla 2. Concentraciones de benceno, tolueno y xileno en aire en las empresas participantes, Bogotá, 2003

\begin{tabular}{|cccc}
\hline Area muestreada & $\begin{array}{c}\text { Benceno } \\
(0,5 \mathrm{ppm})\end{array}$ & $\begin{array}{c}\text { Tolueno } \\
(50 \mathrm{ppm})\end{array}$ & $\begin{array}{c}\text { Xileno } \\
(100 \mathrm{ppm})\end{array}$ \\
\hline $1^{\mathrm{a}}$. Empresa de pinturas \\
Area de producción & & & \\
\hline Area administrativa & 0,01 & 0,13 & 0,17 \\
\hline Area administrativa & 0,01 & 0,25 & 0,47 \\
\hline $2^{\mathrm{a}}$. Empresa de pinturas & 0,01 & 0,12 & \\
\hline Area de producción & & & 5,62 \\
\hline Area de producción & 0,11 & 1,05 & 48,2 \\
\hline Area administrativa & 0,78 & 4,02 & 9,7 \\
\hline $3^{\mathrm{a}}$. Empresa control & 0,02 & 5,70 & 0,01 \\
$\quad$ Area sistemas & & & 0,04 \\
\hline Area administrativa & 0,03 & 0,12 & \\
\hline Fuente: Grupo Salud Ambiental, INS & 0,04 & 0,02 & \\
\hline
\end{tabular}

Comparación entre la condición de exposición y algunas variables

Se encontraron diferencias significativas entre la condición de exposición y género $(p=0,017)$, edad $(p=0,02)$, tiempo de trabajo en la empresa $(p=0,02)$, tipo de ropa de trabajo $(\mathrm{p}=0,003)$, frecuencia de cambio de ropa de trabajo $(p=0,02)$, uso de guantes $(p=0,03)$, tipo de guantes $(p=0,009)$, uso de respirador $(\mathrm{p}=0,01)$ y ducharse al terminar la jornada de trabajo $(\mathrm{p}=0,001)$. No se encontraron diferencias significativas entre la condición de exposición y lavar la ropa de trabajo mezclada con el resto de ropa $(\mathrm{p}=0,1)$, lugar donde lavan la ropa ( $\mathrm{p}=0,07)$, lavarse las manos antes de ingerir alimentos $(\mathrm{p}=0,06)$, consumo de alimentos en el lugar de trabajo ( $\mathrm{p}=0,4)$, fumar $(\mathrm{p}=0,2)$, fumar en el lugar de trabajo $(p=0,8)$, consumo de licor $(p=0,3)$ y consumo de enlatados $(p=0,08)$. Igualmente, no hubo diferencias significativas con los síntomas reportados por los trabajadores $(p>0,05)$, sin embargo, estos se encontraron con mayor frecuencia en los trabajadores expuestos. No se encontraron diferencias significativas entre la condición de exposición y frecuencia de $\mathrm{MN}(\mathrm{p}=0,5)$ y con la media de longitud de la cola $(\mathrm{p}=0,2)$ en el ensayo del cometa. Estos resultados se encuentran dentro de los rangos descritos en la literatura para poblaciones no expuestas a agentes genotóxicos. No se encontraron diferencias significativas entre la condición de exposición y los niveles de fenol $(\mathrm{p}=0,4)$ y ácido metilhipúrico ( $\mathrm{p}=0,1)$, sin embargo, al comparar con los niveles de ácido hipúrico en muestras de orina post-exposición se hallaron diferencias significativas $(\mathrm{p}<0,01)$. Al observar las variables demográficas, ocupacionales, 
medidas de higiene y seguridad, elementos de protección personal y hábitos en el trabajo de los trabajadores con niveles altos de fenol y ácido metilhipúrico, no se observaron diferencias significativas.

\section{DISCUSION}

Por muchos años el monitoreo biológico de exposición a solventes es realizado midiendo sus metabolitos urinarios específicos, los cuales proveen suficiente sensibilidad y especificidad para vigilancia en salud ocupacional $(35,36)$. Igualmente, el monitoreo citogenético es una herramienta que permite evaluar efectos genotóxicos e identificar riesgos y poblaciones expuestas, indicando acciones que pueden ser tomadas para reducir o eliminar intoxicaciones, así como para fijar límites de exposición ambiental, en estudios de biomonitoreo en humanos (4).

En este estudio se observó que el uso de solventes orgánicos en las empresas participantes se hacía en cantidades pequeñas, sin embargo, se olvida que el riesgo químico es de importancia, lo cual se refleja en el escaso uso de elementos de protección personal e insuficientes medidas de higiene y seguridad que los trabajadores tienen al manipular este tipo de sustancias en el proceso de elaboración de las pinturas. Estos factores podrían contribuir a una exposición crónica a bajas concentraciones, representando una amenaza para la salud, productividad y eficiencia de los trabajadores, considerándose así en un importante problema de salud pública.

Se encontraron niveles por encima de los valores de referencia para ácido metilhipúrico en el 50,8 \% de los trabajadores y para fenol en el 3,3 \%, lo cual pudiera ser atribuido a exposición laboral y extralaboral a solventes orgánicos. Así mismo se observó el consumo de licor y enlatados con mayor frecuencia en el grupo no expuesto lo cual podría estar contribuyendo a la presencia de metabolitos de solventes orgánicos en orina. Se puede considerar que todos los trabajadores se encontraban expuestos a concentraciones ambientales de solventes orgánicos ya que son impurezas en productos como el tiner, adhesivos de pinturas y productos de limpieza. También son usados en el octanaje de la gasolina y se encuentran en el humo del tabaco y el cigarrillo en ambientes cerrados $(37,38)$, convirtiéndose en contaminantes del medio ambiente de trabajo, en el hogar y ambiente en general, lo cual implica exposición indirecta, esto aunado a factores individuales que pueden influir en la eliminación de los metabolitos (39-41), podrían ayudar a explicar su presencia en la orina de trabajadores no expuestos. 
No se observaron diferencias significativas en entre los trabajadores expuestos y no expuestos, los trabajadores que presentaron niveles altos de ácido metilhipúrico en orina y la mayoría de variables estudiadas, y entre otras como género, fumar, consumo de licor y enlatados, lo que pudiera ser explicado por que la población es muy semejante en cuanto a medidas de higiene y seguridad en el trabajo, hábitos en el trabajo y que las concentraciones de BTX, empleadas en el proceso industrial en estas empresas era en concentraciones bajas debido al nivel de producción considerando que son empresas de tipo familiar; sin embargo, las concentraciones de metabolitos encontradas en orina fueron mayores en los que fumaban, consumían licor y enlatados, ya que estas circunstancias que junto a la variabilidad individual fisiológica o metabólica pueden influir en la absorción, metabolismo y eliminación de los metabolitos de solventes orgánicos en orina (36,39-41).

Ninguno de los biomarcadores de efectos genéticos tempranos (frecuencia de $\mathrm{MN}$ y el rompimiento de cadenas sencillas deADN en células mononucleares de sangre periférica) en los trabajadores participantes, se encontró por encima de los valores de referencia para individuos "sanos" no expuestos a agentes genotóxicos $(13,21)$, lo cual concuerda con lo reportado en la literatura en estudios con iguales resultados, en donde no se detectó inducción de MN y daño en el ADN en linfocitos de policías de tránsito expuestos a concentraciones de benceno $(18,42)$. Es posible que concentraciones altas de benceno deban estar presentes para poder detectar un efecto genotóxico $(16,43)$.

Los niveles de benceno encontrados en las empresas participantes en la presente investigación fueron en general más bajos que los niveles reportados por Bubvik N (43) , solamente en el área de producción de una de las fábricas, se hallaron niveles de 0,78 ppm de benceno, sin embargo, ninguno de los trabajadores de los que laboraban en esta empresa presentó frecuencias anormales de micronúcleos ni rompimiento de cadenas de $\mathrm{ADN}$, lo cual sugiere que la exposición al solvente fue en bajas dosis, por poco tiempo o que otros factores como enzimas desintoxicantes generaron una dosis interna baja de benceno.

Los resultados hallados en este estudio se encuentran dentro de los rangos de los valores de referencia de la población "sana", lo que sugiere que la población estudiada estuvo expuesta a bajas y diferentes concentraciones de solventes orgánicos, que usaban otros solventes diferentes a los monitoreados y que por ser empresas familiares la producción de pinturas es baja, al igual que las cantidades de solventes orgánicos empleadas. Sin embargo, estos 
hallazgos negativos requieren ser confirmados por estudios de tipo analítico donde se evalúe la exposición con mayor número de biomarcadores para detectar pequeñas diferencias entre los grupos de exposición.

Los resultados de éste estudio únicamente son extrapolables a empresas con características similares a las involucradas dentro del mismo. Esta investigación no pretende establecer causalidad sino a partir de los resultados, formular hipótesis de asociación que se evaluarán posteriormente a través de estudios analíticos

Agradecimientos. A los trabajadores y los directivos de las empresas participantes. Igualmente a Sandra Rocha, Julia Arroyo, Claudia Monroy, Andrea Cortés, Ermel Olarte, por el apoyo técnico y logístico y a la Dra. Nelcy Rodríguez por la asesoría en el análisis estadístico de los datos. Fuentes de financiación: Este proyecto fue financiado por el Instituto Nacional de Salud de Colombia y cofinanciado por la Universidad El Bosque y la Universidad de los Andes.

Conflicto de intereses: Ninguno

\section{REFERENCIAS}

1. Forster LM, Tannhauser M, Tannhauser SL. Toxicology of toluene: aspects related to its abuse. Rev Saude Publica 1994;28:167-172.

2. Nise G Hogstedt B, Bratt I, Skerfving S. Cytogenetic effects in rotogravure printers exposed to toluene (and benzene). Mutat Res 1991;261:217-223.

3. Pitarque M, Vaglenov A, Nosko M, Pavlova S, Petkova V, Hirvoren A, et al. Sister chromatid exchanges and micronuclei in peripheral lymphocytes of shoe factory workers exposed to solvents. Environ Health Perspect 2002;110:399404.

4. Pitarque M, Vaglenov A, Nosko M, Hirvonen A, Norppa H, Creus A, et al. Evaluation of DNA damage by the comet assay in shoe workers exposed to toluene and other organic solvents. Mut Res 1999;441:115-127.

5. Pinto D, Ceballos JM, García G, Guzmán P, Del Razo LM, Vera E, et al. Increased cytogenetic damage in outdoor painters. Mut Res 2000;467:105-111.

6. Yager JW, Eastmond DA, Robertson ML, Paradisin WM, Smith MT. Characterization of micronuclei induced in human lymphocytes by benzene metabolites. Cancer Res 1990;50:393-399.

7. Robertson ML, Eastmond DA, Smith MT. Two benzene metabolites, catechol and hydroquinone, produce a synergistic induction of micronuclei and toxicity in cultured human lymphocytes. Mut Res 1991;249:201-209. 
8. Angelosanto FA, Blackburn GR, Schreiner CA, Mackerer CR. Benzene induces a dose-responsive increase in the frequency of micronucleated cells in rat Zymbal glands. Environ Health Perspect 1996;104:1331-1336.

9. Ress NB, Witt KL, Xu J, Haseman JK, Bucher JR. Micronucleus induction in mice exposed to diazoaminobenzene or its metabolites, benzene and aniline: implications for diazoaminobenzene carcinogenicity. Mut Res 2002;521:201208.

10. Hogstedt B, Holmen A, Karlsson A, Raihle G, Nillius K, Vestlund K. Gasoline pump mechanics had increased frequencies and sizes of micronuclei in lymphocytes stimulated by pokeweed mitogen. Mut Res 1991;263:51-55.

11. Pitarque M, Carbonell E, Lapena N, Marsa M, Torres M, Creus A, et al. No increase in micronuclei frequency in cultures blood lymphocytes from a group of filling station attendants. Mut Res 1996;367:161-167.

12 Surralles J, Autio K, Nylund L, Jarventaus H, Norppa H, Veidebaum T, et al. Molecular cytogenetic analysis of buccal cells and lymphocytes from benzene-exposed workers. Carcinogenesis 1997;18:817-823.

13. Da Silva LA, Rocha S, Ruíz M, De Souza CA. Micronucleus monitoring to assess human occupational exposure to organochlorides. Environ Mol Mut 1997;29:46-52.

14. Ning H, Kado NY, Kuzmicky PA, Hsieh DPH. Benzene-Induced micronuclei formation in mouse fetal liver blood, peripheral blood, and maternal bone narrow cells. Environ Mol Mut 1991;18:1-5.

15. Mac Gregor JT, Tucker JD, Eastmond DA, Wyrobek AJ. Integration of cytogenetic assays with toxicology studies. Environ Mol Mut 1995;25:328-337.

16. Andreoli C, Leopardo P, Crebelli R. Detection of DNAdamage in human lymphocytes by alkaline single cell gel electrophoresis after exposure to benzene or benzene metabolites. Mut Res 1997;377:95-104.

17. Valverde M, Ostrosky-Wegman P, Rojas E, Fortoul F, Meneses F, Ramírez M, et al. The application of single cell gel electrophoresis or comet assay to human monitoring studies. Rev Salud Pública de México 1999;41:S109-S113.

18. Carere A, Andreoli C, Galato R, Leopardo P, Marcon F, Rosati MV, et al. Biomonitoring of exposure to urban air pollutants: analysis of sister chromatid exchanges and DNA lesions in peripheral lymphocytes of traffic policemen. Mut Res 2002;518:215-224.

19. Peña G, Varona M, Acosta H, Cárdenas O, Sánchez C, Cardozo M, et al. Evaluación Epidemiológica de la Exposición a solventes orgánicos en fábricas de pinturas y pegantes en Santa Fe de Bogotá. División de Biblioteca y Publicaciones Instituto Nacional de Salud. Documento Técnico. Diciembre de 1996;1-28.

20. Varona M, Cárdenas O, Conde JV, Rossi LV, Idrovo AJ, Araque A, et al. Determinación de la exposición en trabajadores que laboran con solventes orgánicos en 
Bogotá. División de Biblioteca y Publicaciones-Instituto Nacional de Salud. Documento Técnico. Mayo de 2001; 7-33.

21. Fenech M, Morley AA. Measurement of micronuclei in lymphocytes. Mut Res 1985;147: 29-36.

22. Singh NP, McCoy MT, Tice RR, Schneider EL. A simple technique for quantitation of low levels of DNA damage in individual cells. Exp Cell Res 1988;175:184191.

23. National Institute Occupational Safety and Health, Centers Disease Control. Phenol in urine. Manual of Analytical Methods, Vol. 6. USA.; 1980. pp. 330-331.

24. National Institute Occupational Safety and Health, Centers Disease Control. Hippuric and methyl hippuric acids in urine. Method 8301. Manual of Analytical Methods, Fourth Edition, Vol. 1. USA.; 1984. pp 1-4.

25. Acosta H, Ortiz J. Determinación de fenol y ácidos hipúrico y metil hipúrico en orina mediante técnicas cromatográficas (GC-FID y HPLC-UV). Manual de procedimientos. Metabolitos de solventes orgánicos (benceno, tolueno y xileno).Bogotá D.C.: Instituto Nacional de Salud de Colombia; 1996.

26. Head SLT. Phenol, o-cresol, m-cresol, and p-cresol in urine. Methods for Biological Monitoring. A Manual for Assessing Human Exposure to Hazardous Substances. First Edition. Washington, DC,: American Public Health Association. Library of Congress Cataloging-in-Publication Data; 1998. pp 347-351.

27. Bailey SL. Hippuric and methylhipuric acids in urine. Methods for Biological Monitoring. A Manual for Assessing Human Exposure to Hazardous Substances. First Edition. Washington, DC,: American Public Health Association. Library of Congress Cataloging-in-Publication Data; 1998. pp 381-386.

28. Organización Mundial de la Salud. Límites recomendados por razones de salud en la exposición profesional a determinados solventes orgánicos. Serie de informes técnicos 664. Ginebra, Suiza: Editorial Gráficas Reunidas S.A.; 1982. pp 28-43.

29. National Institute Occupational Safety and Health, Centers Disease Control. Hydrocarbons, Aromatic. Method 1501. Manual of Analytical Methods. Four Edition. Vol. 2. USA.; 1996. pp 1-7.

30. Rock JC. Occupational air sampling strategies. Air sampling instruments for evaluation of atmospheric contaminants. In: Cohen BS, Hering SV (editors). Eighth Edition. Cincinnati: ACGIH; 1995. pp 20-44.

31. National Institute Occupational Safety and Health, Centers Disease Control. Organic solvents in air. Method 127. Manual of Analytical Methods, Second Edition, Vol. 1.USA; 1977.pp 1-7. 
32. Ministerio de Trabajo y Seguridad Social, Ministerio de Salud. Determinación de las bases para la organización y administración de Salud Ocupacional en el país. Decreto No. 614 de marzo 14 de 1984. V parte, Bogotá, D.C.; 1984. pp 149-169.

33. American Conference of Governmental Industrial Hygienists. TLVs and BEIs. Threshold Limit Values for Chemical Substances and Physical Agents Biological Exposure Indices. Cincinnati, OH; 1999. pp 19, 67, 72.

34. Sandmeyer EE. Aromatic hydrocarbons. Patty's Industrial Higiene and Toxicology. Third Edition, Vol. 2. USA: Clayton Edit; 1981, pp. 3260-3298.

35. Kramer A, Linnert M Jr, Wrbitzky R, Angerer J. Occupational chronic exposure to organic solvents ambient and biological monitoring of workers exposed to xylenes. Int Arch Occup Environ Health 1999;72:52-55.

36. Langman JM. Xylene: its toxicity, measurement of exposure levels, absorption, metabolism and clearance. Pathol. 1994;26:301-309.

37. Greenberg MM. The central nervous system and exposure to toluene: A risk characterization. Environ Res 1997;72:1-7.

38. Yardley JA, Anderson D, Parker DV. The toxicity of benzene and its metabolism and molecular pathology in human risk assessment. Br J Ind Med 1991;48:437444.

39. Droz PO, Wu MM, Cumberland WG. Variability in biological monitoring of organic solvent exposure. II application of a population physiological model. Br J Ind Med 1989;46:547-558.

40. Perbellini L, Ghittoris S. Il monitoraggio biologico delle esposizioni professionali a solventi utilizzando le loro concentrazioni urinarie. Med Lav 1998;89:375-386.

41. Droz PO, Wu MM, Cumberland WG, Berode M. Variability in biological monitoring of solvent exposure. I development of a population physiological model. $\mathrm{Br} \mathrm{J}$ Ind Med 1989;46:447-460.

42. Leopardi P, Zijno A, Marcon F, Conti L, Carere A, Verdina A, et al. Analysis of micronuclei in peripheral blood lymphocytes of traffic wardens: effects of exposure, metabolic genotypes, and inhibition of excision repair in vitro by ARA-C. Environ Mol Mutagen. 2003;41:126-130.

43. Bukvic N, Bavaro P, Elia G, Cassano F, Fanelli F, Guanti G Sister chromatid exchange (SCE) and micronucleus (MN) frequencies in lymphocytes of gasoline station attendants. Mut Res. 1998;415:25-33. 